\title{
O DESENCANTAMENTO MORAL DA ESCOLA PÚBLICA: UM ENSAIO DE COMPREENSÃO CRÍTICA ${ }^{1}$
}

\author{
THE MORAL DISENCHANTMENT OF THE PUBLIC SCHOOL: \\ AN ESSAY OF CRITICAL COMPREHENSION \\ EL DESENCANTAMIENTO MORAL DE LA ESCUELA PÚBLICA: \\ UN ENSAYO DE COMPRENSIÓN CRÍTICA
}

\section{Gabriel Lelis da Fonseca Ferreira ${ }^{2}$ Carlos Alberto Lopes Sousa ${ }^{3}$}

RESUMO: Este ensaio, trabalhado segundo a perspectiva de uma sociologia compreensiva e crítica, pretende contribuir para o entendimento e a crítica de tendência recente observada na escola básica brasileira, aqui denominada "desencantamento moral". Trata-se de um fenômeno social que significa a progressiva "redução da diversidade moral" das escolas básicas, em virtude de uma reconfiguração, tanto da demanda educacional da sociedade, como da oferta institucional das escolas. Ambas pressionando no sentido da gênese de um novo tipo de educação moral, em cujos contornos, mais ou menos uniformes, transparecem traços de uma "ética empresária". Esta ética tende a conceber a educação escolar cada vez mais como "prestação de serviço", e menos como "formação humanística". Confere-se, neste ensaio, particular atenção ao caso da "escola pública", que vem, progressivamente, assumindo certos aspectos morais da chamada "escola-empresa", nesse movimento geral de homogeneização da diversidade moral escolar no Brasil. A análise dos efeitos de desencantamento sobre a escola pública é feita em perspectiva comparativa, em vista dos mesmos efeitos sobre outros tipos escolares: da "escola católica" e "militar".

PALAVRAS-CHAVE: Educação moral. Escola pública. Escola-empresa. Desencantamento.

ABSTRACT: This essay, which is based upon the perspective of a comprehensive and critical sociology, aims to contribute to the understanding and critique of a recent trend in Brazilian elementary school, herein called "moral disenchantment". This is a social phenomenon that represents the gradual "reduction of moral diversity" in elementary schools due to a reconfiguration of both the educational demands from the society and the institutional offer of schools. Both press for the genesis of a new kind of moral education, whose contours, more or less uniform, reveal traces of a "business ethics". This ethics tends to conceive of education increasingly as the "delivery of a service" and less as "humanistic formation". In this essay, particular attention is given to the case of "public school", which has gradually come to assume certain moral aspects of the so-called "school-enterprise", in this

\footnotetext{
${ }^{1}$ Este texto tem como base o artigo anterior "Crítica de uma tipologia moral da escola básica no Brasil atual", de autoria destes mesmos autores, apresentado no III Colóquio Luso-Brasileiro de Sociologia da Educação, a 26 de julho de 2012, na Universidade Federal do Rio de Janeiro (UFRJ), sendo revisto para fins desta publicação.

${ }^{2}$ Graduando em Sociologia pelo Instituto de Ciências Sociais da Universidade de Brasília (UnB). Brasília (DF). E-mail: lelis.gabriel@live.com

${ }^{3}$ Doutor em Ciências Sociais (Sociologia) pela PUC - São Paulo. É professor de Sociologia da Educação, atuando no Departamento Teoria e Fundamentos (TEF) da Faculdade de Educação da Universidade de Brasília (UnB) e integra o Programa de Pós-Graduação em Educação (PPGE). Brasília (DF). E-mail: carloslopes@unb.br
}

Submetido em: 23/06/2014 - Aceito em: 14/08/2014. 
general movement of homogenization of school moral diversity in Brazil. The analysis of the effects of disenchantment on the public school is carried out in a comparative perspective, given the same effects on other types of school: the "Catholic school" and "military" school".

KEYWORDS: Moral education. Public school. School-enterprise. Disenchantment.

RESUMEN: Este ensayo, trabajado según la perspectiva de una sociología comprensiva y crítica, pretende contribuir al entendimiento y la crítica de tendencia reciente observada en la escuela básica brasileña, denominada aquí "desencantamiento moral". Se trata de un fenómeno social que significa la progresiva "reducción de la diversidad moral" de las escuelas básicas. Esto, en virtud de una reconfiguración, tanto de la demanda educacional de la sociedad, como de la oferta institucional de las escuelas. Ambas presionando en el sentido de la génesis de un nuevo tipo de educación moral, cuyos contornos, más o menos uniformes, dejan transparentar trazos de una "ética empresarial". Esta ética tiende a concebir la educación escolar cada vez más como "prestación de servicio" y menos como "formación humanística". Se le atribuye, en este ensayo, una particular atención al caso de la "escuela pública" que viene asumiendo, progresivamente, aspectos morales de la llamada "escuela-empresa", en ese movimiento general de homogenización de la diversidad moral escolar en Brasil. El análisis de los efectos de desencantamiento sobre la escuela pública se realiza bajo la perspectiva comparativa, en vista de los mismos efectos sobre otros tipos escolares: de la "escuela católica" y "militar".

PALABRAS-CLAVE: Educación moral. Escuela pública. Escuela-empresa. Desencantamiento.

\section{INTRODUÇÃO}

O destino de nossos tempos é caracterizado pela racionalização e, acima de tudo, pelo 'desencantamento do mundo', [em que] os valores últimos e mais sublimes retiraram-se da vida pública (...). (WEBER, 1982, p. 182, grifo nosso).

Há certo consenso paradigmático em teoria social, mais ou menos transversal a seus diferentes matizes, segundo o qual as sociedades modernas são caracterizadas pela crescente diferenciação e especialização de diferentes naturezas. Sergio Tavolaro apresenta, em um artigo recente ${ }^{4}$, uma espécie de síntese das principais ideias de Durkheim, Habermas, Weber, Bourdieu, entre outros, que concordam nesse sentido. Trata-se da crescente complexidade adquirida pelas esferas econômica, política, cultural e, o que é de especial interesse à reflexão que aqui se introduz. Sinaliza-se também para a vertiginosa diferenciação e moral da vida social moderna ${ }^{5}$, originando o que Durkheim denomina densidade moral, que nada mais é do que a diversidade de tipos morais no seio de uma sociedade. Há, por exemplo, a moral militar, as morais cristãs, as morais empresariais, entre numerosas outras. São tão diversas quanto o são as instituições às quais elas estão relacionadas, como as Forças Armadas, as

\footnotetext{
${ }^{4}$ Tavolaro (2005).

${ }^{5}$ Importante elemento da tese central do clássico estudo de Émile Durkheim (DURKHEIM, 1995).
} 
igrejas, as empresas. E, em face dessa crescente complexidade moral, ou paralelamente a ela, são desenvolvidos diversos mecanismos sociais para lhe corresponder: uma vasta miríade de instituições políticas, religiosas, educativas, entre outras, que são, a um só tempo, produto e causa daquela diferenciação moral. Este ensaio procura se debruçar especificamente sobre o âmbito da educação moral no Brasil, mais precisamente, sobre uma particularidade histórica peculiar nesse amplíssimo âmbito social. Trata-se de um movimento tendencial observado no contexto da escola básica - leia-se, fundamental e média - no Brasil atual. Partindo da fundamentada argumentação de Tavolaro (2005) de que sociedade brasileira urbana de hoje preenche os requisitos de uma sociedade dita moderna, é natural que suas instituições educativas apresentem, atual e empiricamente, um elevado grau de "diferenciação e especialização moral" (DURKHEIM, 1955). Tais instituições moralmente diversas, aos níveis elementares - as quais serão aqui denominadas "escolas" -, são, em parte, fruto da diversidade social existente na sociedade brasileira moderna e, simultaneamente, são também responsáveis por reproduzir essa mesma diversidade. Dito de outro modo há, por um lado, uma demanda educacional dos segmentos sociais diferenciados por determinados tipos de educação moral que melhor lhe correspondam moralmente - a diversidade moral escolar é, pois, fruto de uma diversidade moral social que a ultrapassa e engloba. E, por outro lado, há também o interesse institucional daquelas escolas básicas em formar indivíduos segundo determinada moral, qualitativamente específica, de tal modo que esta diversidade moral escolar também corrobora para reproduzir aquela mesma diversidade moral da sociedade como um todo. Essas duas potências, a saber, a demanda educacional dos sujeitos, indivíduos e famílias, e o interesse institucional, das escolas, por certo tipo de educação moral, são as grandes responsáveis pelo cenário moral da educação básica no Brasil de hoje, podendo se combinar de diferentes maneiras, tanto se equivalendo quanto se sobrepondo uma à outra ${ }^{6}$. A supracitada tendência, ou movimento tendencial sobre o qual este trabalho se ocupa, diz

\footnotetext{
6 Trata-se, grosso modo, de uma relação análoga à própria relação mercadológica de oferta e demanda, figurando a primeira como o interesse institucional, a oferta de certo tipo de educação moral pelas escolas básicas, e esta última correspondendo à demanda educacional da sociedade que se quer educar. A história traz vários exemplos tanto de realidades em que oferta e demanda se equivaleram harmonicamente - uma correspondendo bem à outra -, quanto de realidades em que uma se sobrepôs à outra - ou seja, em que o interesse institucional impôs certo tipo de educação moral sobre a sociedade ou sobre alguns de seus segmentos; ou em que a demanda educacional da sociedade ou de alguns segmentos pressionou no sentido do advento e fomento de certa educação moral.
} 
respeito à reconfiguração de ambos, demanda e interesse, no contexto da educação básica no Brasil atual, privilegiando-se a análise sobre a escola pública. Trata-se, pois, de uma reconfiguração histórica daquelas duas potências determinantes cujo resultado aponta, como aqui se procurará argumentar, na direção da redução da diversidade moral da educação básica no Brasil do presente ${ }^{7}$. Com enfoque conferido à situação da escola pública, deseja-se aqui compreender semelhante movimento tendencial de homogeneização moral da educação pública brasileira ao nível básico, fenômeno aqui chamado desencantamento moral.

Este breve estudo parte de uma descrição tipológica de dois tipos ideais referentes a duas espécies de éticas morais, que engendram vários tipos de educação moral. A fim de se conceber e de se distinguir esses dois tipos, será abordado o ponto de vista do interesse institucional, colhendo-se da "oferta" os elementos necessários à configuração de um quadro aproximativo da educação moral que é oferecida por ambos os tipos na realidade. Em cada um desses dois contextos, identifica-se um tipo específico de ética moral, isto é, determinada maneira de ser e de proceder moralmente de cada uma das instituições aqui discutidas, a saber, a escola pública e a escola-empresa. Toda a reflexão sobre as suas peculiares éticas morais é elaborada a partir de seus respectivos discursos morais. Estes últimos, derivados daquelas éticas, consistem em textos articulados aos sistemas de normas de conduta de cada escola, que prescreve a seu alunado certos comportamentos em determinadas ocasiões ${ }^{8}$. Esses discursos morais foram acessados mediante pesquisa de análise documental de materiais produzidos pelas próprias escolas. Todos os textos analisados foram colhidos de instituições brasileiras atuais, consideradas as mais emblemáticas e representativas de cada tipo. Enquanto discursos morais, esses textos são analisados em sua composição geral, cujos elementos são as suas formas - isto é, como esses discursos se apresentam ao alunado -, seus conteúdos - o que precisamente eles dizem - e suas razões - por que eles o dizem. Esses três elementos são conjugadamente debatidos nesta narrativa como um todo problemático indissociável. A composição geral dos discursos morais de cada tipo de escola permite configurar um quadro aproximado da composição de sua respectiva e típica ética moral, uma

\footnotetext{
${ }^{7}$ Embora seja a sociedade brasileira uma sociedade crescentemente "moderna", diferenciada, especializada, este texto procurará advogar que interesses e demandas mais ou menos comuns, transversais aos mais diferentes grupos, tendem a conduzir, presentemente, a vasta gama da educação moral brasileira a um tipo homogêneo. A escola pública se insere nesse cenário como um tipo, ao lado de tantos outros, cuja especificidade se desvanece progressivamente com a marcha do tempo, à medida que também se homogeneíza naquela mesma direção.

${ }^{8}$ Referimo-nos, aqui, ao clássico conceito de moral de que se vale Émile Durkheim (DURKHEIM, 1995).
} 
vez que desta se derivam e a ela se referem cotidianamente. Após a caracterização desses dois ideais típicos de éticas morais, referentes a cada tipo diverso de educação moral $^{9}$, esta proposta procura elaborar uma crítica compreensiva em que transparece aquela tendência de desencantamento moral da escola pública, ou seja, a tendência segundo a qual a escola pública vem paulatinamente assimilando certos traços típicos da escola-empresa na atualidade. Isso se deve, como se procurará argumentar, a uma dupla reconfiguração de ambas as potências, nomeadamente, da demanda educacional dos sujeitos - diretamente atrelada às suas necessidades educacionais concretas - e da oferta institucional. Ambas as potências têm pressionado cada vez mais no sentido daquela crescente assimilação, por parte da escola pública, da moralidade oriunda da escola-empresa. Assimilação que tem implicado no inelutável e iniludível desencantamento moral da escola pública, no sentido de que os seus valores mais sublimes vão cedendo espaço à mentalidade contratual e racional da educação escolar entendida preferencialmente como prestação de serviço, voltada, pois cada vez mais à capacitação prática e menos à formação humanística do alunado. Por ambos os lados, da oferta e da demanda, as intenções sociais que orientam essa transformação estão, de algum modo, como se verá, associadas a um recente e vertiginoso pragmatismo da vida na sociedade brasileira moderna. Princípio esse que vem auferir da vida pública os "valores últimos e mais sublimes" (WEBER, 1982) da diversidade moral, reduzindo-a à homogênea racionalidade contratual, pragmática, despojada de fórmulas e ideias sublimes ou transcendentais. Significa dizer que a vida pública passa a se conduzir cada vez menos por ideais morais válidos por si mesmos - como as noções de honradez, de espiritualidade, de civismo -, e cada vez mais por um simples pragmatismo concreto, que opera segundo um cálculo racional entre meios e fins.

\footnotetext{
${ }^{9}$ Os quatro aspectos da composição dos discursos e éticas morais são acompanhados, cada um, por elementos voltados à compreensão acurada dos diferentes tipos de educação moral. Sobre os atores, reflete-se sobre o papel que é desempenhado pelas escolas como meio entre a moralidade de suas respectivas instituições matrizes - a saber, o Estado Democrático de Direito e Economia Capitalista, das quais se derivam os tipos morais das escolas pública e católica, respectivamente - e a juventude, em processo de socialização, para quem a educação moral é ofertada. Quanto ao conteúdo desses discursos, apresentam-se várias adjetivações descritivas e normativas do alunado em cada caso, apresentadas por cada tipo de discurso e de ética moral. Com respeito à forma, trata-se de várias estratégias de produção e reprodução da crença na legitimidade (WEBER, 2009) dos discursos e éticas morais no âmbito de cada escola. Finalmente, discutem-se as razões por trás desses mesmos discursos e éticas: as pretensões de cada escola de engendrar um núcleo de sociabilidade segundo sua moralidade, como um projeto desejável de sociedade, concebendo a socialização como a pedra angular da mudança social pela via moral.
} 


\section{CONCEPÇÃO E DIFERENCIAÇÃO TíPICA DAS ÉTICAS MORAIS}

\subsection{A ética moral da escola pública}

A ética moral da escola pública pode ser sondada mediante a análise da forma, do conteúdo e das razões dos discursos morais produzidos pela mesma escola. Quanto a sua forma, tais discursos, no contexto da escola pública, apresentam-se ao alunado, somam-se dinâmicas e cursos regulares de cidadania, de ética e de civismo; campanhas em defesa de certas causas cidadãs; além de excursões e visitas a locais que guardam certo interesse moral - capazes de reforçar certos valores; e ainda discursos de autoridades direta ou indiretamente ligadas ao Estado. É comum, por exemplo, haver nessas escolas pronunciamentos de autoridades ligadas a projetos públicos de incentivo à educação, em feiras ou oficinas científicas ou de cunho mais humanista, onde se observam manifestações discursivas banhadas pela moral do Estado. No que tange ao conteúdo descritivo e normativo dos discursos, a escola pública procura em geral projetar as qualidades morais que mais aprecia em um tipo de aluno idealizado. Em tal projeção transparece o tipo de aluno moralmente apreciado no bojo da escola pública, o modelo que deve moralmente ser seguido por todos os alunos. Trata-se do cidadão engajado, o aluno que se interessa tanto pela rotina política e social da escola quanto da sociedade, para ambas contribuindo participativamente. Às suas credenciais, somam-se ainda, os valores de cidadania, respeito, inclusão, responsabilidade, cooperação, solidariedade, tolerância e participação ${ }^{10}$. Os propósitos típicos da moral da escola pública dirigem-se, por definição, e em última instância, à formação da consciência cidadã dos alunos, consciência adequada ou conformada à moral do Estado Democrático de Direito $^{11}$.

Deseja-se incutir nos discentes a ciência da importância do conhecimento das normas e leis, tanto ao nível da escola quanto ao nível do Estado. Cumpre conhecer e respeitar as leis

\footnotetext{
10 "São princípios fundamentais estabelecidos nas Diretrizes Curriculares Nacionais para a organização do trabalho pedagógico da Educação Infantil: d) Princípios éticos: valorização da autonomia, da responsabilidade, da solidariedade e do respeito ao bem comum, ao meio ambiente e às diferentes culturas, identidades e singularidades. e) Princípios políticos: dos direitos de cidadania, do exercício da criticidade e do respeito à ordem democrática.'(Cf. Informação no sítio eletrônico da SEDF. Disponível em:< http://www.se.df.gov.br/?page id=193>. Acesso em: 10 maio 2014).

11 "A educação básica é o caminho para assegurar a todos os brasileiros a formação comum indispensável para o exercício da cidadania e fornecer-lhes os meios para progredir no trabalho e em estudos posteriores" (Cf. Informação no sítio eletrônico do MEC. Disponível em: <http://portal.mec.gov.br/index.php?option= com content\&view=article\&id=293\&Itemid=358>. Acesso em: 16 jan. 2014).
} 
bem como seus processos de elaboração e legitimação. O processo de elaboração e legitimação, no que diz respeito ao conhecimento e respeito às normas e leis, corresponde à moral convencional. Essa moral convencional, referenciada nos termos de Kohlberg (1982), representa apenas um dos níveis de evolução do desenvolvimento da moralidade ${ }^{12}$, orientada para a manutenção da ordem social. Portanto, pressupõe que o indivíduo tem consciência da existência das regras sociais e da exigência da sua internalização. A ação moral tida como correta pelo indivíduo é aquela determinada por autoridades - pessoas, instituições reconhecidas socialmente e referida às expectativas do sujeito em relação grupo social (KOHLBERG, 1982). Alimentam-se a confiança na justiça e bondade intrínseca dessas, e também a confiança na eficácia da participação popular, individual e coletiva, como meio de se alcançar melhorias sociais. Esses discursos morais procuram ainda forjar a noção de pertencimento a uma comunidade política, cuja permanente manutenção é responsabilidade de todos. O "aluno-modelo" que é descrito por tais discursos é aquele entregue ao engajamento laico no mundo. Trata-se do aluno informado sobre as questões prementes à escola e ao Estado, procurando delas participar como cidadão ativo e consciente. Também é um valor fundamental à ética moral da escola pública a meritocracia, pois é pelo mérito pessoal, e não por favorecimentos de qualquer ordem, que os alunos são ensinados a conquistar espaços e se destacar entre os demais. O mérito é, aliás, o princípio pelo qual o Estado preenche e organiza seus quadros - sobremodo pelo mérito de natureza técnica, de sua burocracia. E as premiações, ainda que raras - ao cabo de gincanas esportivas ou de olimpíadas do conhecimento -, vêm legitimar alguns dos aspectos apontados acima, uma vez que por elas se reafirma o mérito como meio privilegiado de se obter sucesso. Outro aspecto característico trazido pelos discursos morais da escola pública é a sua cultura inclusiva, associada à valorização do respeito, da tolerância e da diversidade. Nesse sentido, cada aluno é chamado a conviver com qualquer outro indistintamente, aceitando todo gênero de

\footnotetext{
12 Kohlberg (1982) aponta seis estágios de desenvolvimento moral, agrupados em três níveis: o préconvencional (esse nível que tem o estágio 1 e 2, corresponde, por exemplo, ao que o indivíduo julga o certo e o errado, fundamentado em seus interesses próprios); o convencional (estágio 3 e 4, nível já citado no corpo do texto) e o pós-convencional (estágio 5 e 6, sendo nível corresponde ao agir centrado na observância de princípios morais universais). Vale frisar que nosso ensaio não se funda na abordagem psicológica moral (cognitivo-evolutiva) dos indivíduos e sim no ponto de vista do interesse institucional.
} 
alteridade $^{13}$. Dentre os mecanismos de legitimação pelos quais a ética moral da escola pública deve se tornar inviolável à consideração dos alunos, estão a coerção, a bonificação e a reiteração. A sublimação dos discursos vem vinculá-los a elevados valores impessoais e gerais, pertinentes à comunidade política. Tornam-se assim normas-fetiches, cuja existência e vigência se afastam das consciências individuais, exercendo sobre elas elevada coerção. Considera-se, que, por serem as normas da escola as do Estado, obra de todos os cidadãos, há nelas algo que se desprende das decisões e vontades particulares, de molde a configurar uma vontade geral que não se confunde com as primeiras, possuindo ascendência sobre elas, muito embora seja por elas composta. Enfim, todos esses aspectos de atores, forma e conteúdo servem bem às razões do discurso moral da escola pública no sentido de conformar um peculiar núcleo de sociabilidade em seu interior. Neste caso, trata-se de um espaço sob a atmosfera ética moral formada e informada pelo Estado Democrático de Direito. Uma comunidade civil, cidadã, participativa, responsável, inclusiva e meritocrática ${ }^{14}$.

\subsection{A ética moral da escola-empresa}

A escola-empresa apresenta uma ética moral naturalmente plena de valores mercadológicos e burgueses, inescapavelmente influenciados, condicionados ou determinados pela sua situação social, que não é civil, mas econômica. Tal instituição compartilha da moral empresária típica de qualquer companhia prestadora de serviços no contexto maior e matricial da Economia Capitalista. Exerce-se moralmente, pois, segundo os valores, preceitos e ideais burgueses, enquanto contribui para a socialização do alunado ${ }^{15}$. Quanto à forma dos discursos morais relativos à escola-empresa, há que se assinalar o seu

\footnotetext{
${ }^{13}$ Conforme é possível localizar em certo documento que a escola pública tem como missão auxiliar "na sensibilização da comunidade escolar para a educação inclusiva, favorecendo sua implementação no contexto educativo" (Cf. Informação no sítio eletrônico da SEDF, Regimento Escolar SEDF. Título I. Cap. IV. Seção II. Art. 27. p.26. Disponível em:< http://antigo.se.df.gov.br/sites/400/402/00002676.pdf $>$. Acesso em: 10 maio 2014).

${ }^{14}$ Em um artigo de certo regimento se lê que "A orientação educacional integra-se ao trabalho (...) [de] identificação, na prevenção e na superação dos conflitos, colaborando para o desenvolvimento do aluno, tendo como pressupostos o respeito à pluralidade, à liberdade de expressão, à orientação, à opinião à democracia da participação (...)". (Cf. Informação no sítio eletrônico da SEDF, Regimento Escolar SEDF. Título I. Cap. IV. Seção II. Art. 26. p.26. Disponível em:< http://antigo.se.df.gov.br/sites/400/402/00002676.pdf >. Acesso em: 10 maio 2014).

${ }^{15}$ Em certa passagem do documento, lê-se que determinada escola desse tipo tenciona "Prover soluções, em educação, adequadas às necessidades das pessoas e instituições. [...] Ser uma referência em soluções educacionais e resultados empresariais" (Cf. Informação no Sítio eletrônico da Rede Pitágoras. Disponível em: <http://www.pitagoras.com.br/\# ontem>. Acesso em: 11 maio 2014).
} 
caráter eminentemente publicitário. Trata-se de um apelo que se quer sedutor ante a sociedade e ante o alunado, recorrendo aos interesses e expectativas individuais, familiares, ligadas a um futuro próspero, repleto de sucessos, conquistas, realizações individuais, despreocupado com todo tipo de dever cívico atrelado à comunidade política. E, no que tange ao conteúdo normativo e descritivo dos discursos morais da escola-empresa, prima-se pelos valores de livre-iniciativa, competitividade, empreendedorismo, individualismo, inovação, eficiência e competência. Seu aluno-modelo é aquele que faz o melhor uso - o uso ótimo - ou consumo da mercadoria oferecida pela escola-empresa, sem prejudicar o consumo dos outros ou o patrimônio escola. Trata-se aqui do aluno-consumidor consciente e capacitado. Pretende-se formar um indivíduo suficientemente competitivo e apto, cujo êxito deverá trazer maior publicidade à escola. Aliás, neste tipo de escola, o trabalho em equipe e a cooperação tendem a ser preteridos em benefício do individualismo e da competição entre alunos. As qualidades morais com as quais a escola-empresa se descreve e aos seus alunos corroboram para a forma dos discursos, reforçando seu caráter publicitário inequívoco.

No âmbito da escola-empresa, a moralidade não é, como no caso precedente, imbuída de valores sublimes ou transcendentais, isto é, uma moralidade referida a valores sublimados em relação à vida concreta e pragmática. Valores tais como a cidadania, ou o civismo não entram em questão quando considerado o quadro da escola-empresa. Muito antes, esta escola entende o cultivo dessa moralidade como um meio pelo qual os seus alunos deverão conquistar o seu bem-estar particular, privado. O indivíduo (o bom aluno) agiria tendencialmente em conformidade à expectativa instrumental, calculista e individualista do seu papel social ${ }^{16}$. A rigor, no seio da ética moral da escola-empresa, tudo pode ser subordinado à primazia absoluta do indivíduo, a pedra de toque da moral burguesa típica das instituições capitalistas. Os discursos morais dessa escola se subordinam ao cálculo racional do bem-estar, que articula a moralidade como meio que serve ao fim do sucesso profissional e pessoal, tanto dos alunos quanto da escola-empresa. Pois, se há uma moral e suas normas, elas também se destinam ao desempenho bem sucedido da empresa e à manutenção permanente do negócio. A transgressão moral é desconfortável para os demais consumidores e custosa à empresa. O aluno-modelo desse tipo de escola é, portanto, o "consumidor consciente", que não prejudica o consumo dos seus colegas nem o patrimônio da empresa. E

\footnotetext{
${ }^{16}$ Novamente temos aqui uma aproximação pontual às ideias de Kohlberg (1982).
} 
também é capacitado, por que é de seu sucesso pessoal que depende o fomento da publicidade da escola. As máximas morais de que se vale a escola-empresa servem a ela como slogan e como meio funcional de consecução de seus objetivos, ao lidar com a administração de sua mercadoria ou dos serviços que presta. Além da forma ordinária que possui alguns de seus mecanismos de legitimação do discurso - como sanções, premiações e reiteração -, a escola-empresa guarda significativa peculiaridade no quesito de sublimação dos discursos morais. Isso porque sua ética e seus respectivos discursos morais são sumamente pragmáticos, vazios de qualquer simbolismo transcendental, alimentados apenas pelo princípio da primazia do indivíduo, mirando seu conforto, seu bem-estar. Os alunos, na condição de consumidores e de clientes da escola, são estimulados e coagidos a operar da maneira que melhor convém aos seus interesses pessoais e ao sabor dos negócios da empresa escolar. E a socialização deles compreende máximas e normas de comportamento ordinárias, cujo fim, contudo, não se identifica, como no caso da escola pública, com o exercício da cidadania plena, mas, isto sim, com o pleno bem-estar coletivo e individual, a ser assegurado pelo consumo consciente e satisfatório dos alunos, de modo a proporcionar o seu sucesso, o destaque de cada um e o concomitante sucesso e destaque da escola-empresa, interessada em resultados que indiquem seu êxito e que nutram a sua publicidade. Desse modo, a moralização lhe serve como meio, um instrumento voltado ao fim do sucesso e do bem-estar individual, forjando assim um núcleo de sociabilidade cuja atmosfera moral é qualificada por valores que exortam o alunado à busca pelo seu sucesso individual, sua satisfação privada, tais como o individualismo, o empreendedorismo, a livre-iniciativa. Atmosfera que tende a conformar uma "microssociedade" burguesa de prestadores de serviços e de consumidores conscientes, individualistas, responsáveis, competitivos, empreendedores ${ }^{17}$.

\section{DESENCANTAMENTO MORAL DA ESCOLA PÚBLICA}

As instituições escolares, entre elas as escolas básicas, não operam no vazio social, em que tudo o que importa são os seus interesses morais sobre o corpo discente: com efeito, elas

\footnotetext{
17 As características típicas das éticas morais das escolas pública e empresa, consideradas em sua pureza abstrata, não são de todo incompatíveis e adversas: em ambas, por exemplo, é possível notar elementos simpáticos à ideia de meritocracia, valorizando-se o esforço individual dos alunos como chave para o sucesso pessoal. A seção seguinte, no entanto, se ocupa de tratar os dois tipos como radicalmente distintos, procurandose, mediante esta opção metodológica, salientar a conversão da ética moral típica da escola pública em um tipo diverso, desviante em relação a si próprio.
} 
dependem invariavelmente desse alunado para continuar sua obra de educação e socialização. A frequência dos estudantes nas escolas, porém, depende em boa medida de suas necessidades educacionais concretas, e de suas respectivas famílias. Essas necessidades geram demandas educacionais por determinado tipo de educação moral, demandas essas que precisam ser bem consideradas pelas escolas, sob pena de fracassarem ante um quadro de oferta educacional com pouca ou nenhuma demanda. Aquelas necessidades educacionais, porém, em muito dependem do perfil dos alunos e de suas respectivas famílias: dependendose das aspirações individuais e familiares, pode-se desejar uma educação cristã, civil, patriótica, entre outros tipos, cada um deles mobilizando uma série de componentes requeridos por diferentes grupos sociais para o processo de socialização de seus filhos - suas novas gerações. No caso da escola-empresa, e de outros tipos de escola em estágio mais avançado de desencantamento moral, como a escola católica, o perfil das famílias e do alunado caracteriza-se por segmentos sociais mais bem aquinhoadas, cujas necessidades educacionais concretas já pressionam, há mais tempo, no sentido da maior capacitação dos alunos, em detrimento de sua formação atrelada a valores e princípios morais sublimes ou transcendentais. Suas demandas educacionais acusam, portanto, elementos de apreciável pragmatismo e de primazia do indivíduo, acompanhadas de perto pela reconfiguração dos interesses institucionais das escolas em oferecer uma educação moral cada vez mais pautada por esses elementos - tanto para atender à demanda, alimentando-a, quanto para fomentá-la ${ }^{18}$. Se a escola militar, por exemplo, ainda conserva a sua ética moral razoavelmente afastada dessa tendência de desencantamento, isso se deve, novamente, às necessidades educacionais diversas desses discentes, de suas famílias, bem como dos diversos interesses da instituição. Aqui, no caso da ética moral da escola militar, os valores morais sublimes da educação moral

\footnotetext{
18 A escola católica está, destarte, atualmente mais próxima da escola de tipo empresa, mediante a reconfiguração histórica da demanda do alunado, de suas famílias - entre as quais o catolicismo como orientação moral apresenta-se cada vez mais raro -, e da consoante à reconfiguração da oferta e do interesse institucional das escolas católicas, que vêm paulatinamente substituindo sua ética moral de cunho mais tradicional, inspirada pelos valores católicos, por uma ética moral de caráter mais empresarial, técnico e pragmático, de contrato entre consumidores (alunos e famílias) e prestadores de serviço (instituição escolar).
} 
militar não chegaram a ser decisivamente ameaçados pelas pressões racionais e mercadológicas, imbuídas de exacerbado pragmatismo e individualismo ${ }^{19}$.

Refletindo-se, enfim, sobre a situação moral da escola pública, segundo a perspectiva aqui adotada, é possível identificar uma manifestação intermediária entre os casos das escolas católica e militar, sucintamente tratados acima. Pois, se é verdade que a escola pública já não conserva mais uma ética moral "quase intacta" em seus valores, preceitos, princípios, como a escola militar, também o é que ela não está em uma marcha tão convicta de desencantamento moral, tal como a escola católica. O curioso "caso médio", por assim dizer, da escola pública sinaliza para o início de um novo processo, cujos primeiros contornos apenas começam a se desenhar no horizonte da educação brasileira. Significa que a escola pública também tem se inserido nessa ampla tendência de desencantamento moral da educação, uma vez que sua ética moral peculiar tem progressivamente assumido alguns traços característicos da ética moral da escola de tipo empresa. Dito de outro modo, a forma, o conteúdo e as razões dos discursos morais da escola pública vêm paulatinamente também assimilando as características típicas dos discursos morais da escola-empresa. Tem se mostrado recorrente, por exemplo, certo apelo publicitário discursivo frisando as crescentes competências da escola pública no sentido de capacitar seu alunado à aprovação em concursos vestibulares. Desse modo, a forma publicitária traz um conteúdo marcadamente pragmático, individualista, isto é, recorre aos interesses pessoais de realização do indivíduo, de seu sucesso profissional futuro. A promessa de uma educação eminentemente cidadã, vinculada a ideais, valores e preceitos morais sublimes voltados ao engajamento na comunidade política, é, pois, preterida em benefício da promessa de conforto e de bem-estar futuro, conquistados pela competência, capacidade e destaque individual. E as razões típicas por trás dos discursos e da ética moral da escola pública, de conformar um núcleo de sociabilidade regulado pela moral cidadã, também se convertem, quase imperceptivelmente, em razões mais ligadas à prestação de serviço - ainda que público - pela instituição escolar aos alunos e famílias consumidoras.

\footnotetext{
${ }^{19}$ Relativamente à escola militar, o perfil do alunado e de suas respectivas famílias é bastante peculiar: trata-se, por vezes, de famílias ligadas, de algum modo, às Forças Armadas. Os alunos que frequentam essas escolas são, não raro, filhos de membros do Exército Brasileiro ou de instituições afins. Naturalmente, pois, que entre as necessidades educacionais dessas famílias encontra-se, com pronunciado destaque, a demanda por uma educação moral banhada pelos valores militares. Diferentemente das famílias que confiam seus filhos às escolas católicas - famílias que podem não ser tão veementemente religiosas como no passado -, as famílias que confiam os seus filhos às escolas militares, em regra, orientam-se com rigor segundo a moralidade militar.
} 
Essa modificação dos discursos morais da escola pública, que aponta para a consoante mudança de sua ética moral, deve-se a uma reconfiguração, tanto das necessidades e, logo, da demanda educacional dos alunos e das famílias que se valem dos serviços da escola pública, quanto dos interesses institucionais da escola. Marcio Pochmann aponta com propriedade que o Brasil tem atravessado recentemente uma nada insignificante experiência de mobilidade social (POCHMANN, 2010). Camadas antes pauperizadas e, portanto, privadas do exercício do consumo mais frequente e volumoso, passaram a ascender economicamente, acometidas por um movimento geral de "emburguesamento" ${ }^{20}$, por assim dizer, de natureza econômica, cultural, moral. Desse modo, o perfil da família brasileira cujos filhos frequentam a escola pública tem se alterado nos últimos anos. Essa nova condição, relativa a essas novas camadas sociais, parece ter corroborado para a remodelação de suas diferentes necessidades sociais, entre elas, de suas necessidades educacionais. Tais necessidades, próprias desses setores emergentes, tendem a gravitar na órbita do interesse individual, dos discentes e de seus familiares, pelo sucesso profissional, visando-se o bem-estar, o conforto pessoal dos mesmos discentes no futuro. Há, portanto, como se viu, uma pressão de demanda educacional no sentido de uma educação básica que privilegie a capacitação prática em prejuízo da formação humanística. E a instituição escolar, respondendo a essa demanda - e orientada pelo próprio Estado para atendê-la ${ }^{21}$, termina por remodelar também a sua ética moral e, consequentemente, a qualidade típica da educação moral que oferece, alimentando aquela demanda ao mesmo tempo em que a reproduz. A demanda educacional do alunado e os interesses institucionais da oferta tendem a estabelecer, portanto, um novo equilíbrio mediante essa alteração histórica, contribuindo ambos para a emergência de um novo estado de coisas. Uma conjuntura caracterizada pelo movimento de desencantamento moral da escola pública que, concebido de uma perspectiva mais ampla, significa o atual processo de homogeneização da educação moral ao nível básico no Brasil. É inequívoca a afinidade

\footnotetext{
${ }^{20}$ Expressão cunhada por Alexis de Tocqueville, quando se debruçou sobre o caso americano, no século XIX, lá deslindando uma tendência semelhante (TOCQUEVILLE, 1998).

${ }^{21}$ Enquanto instituição responsável em última análise pela qualidade da escola pública, parece seguro aduzir que o Estado possui certo interesse político nessa mesma remodelação da ética moral de suas escolas. A busca pelos melhores resultados dos alunos em exames internos da escola, bem como aprovações em concursos vestibulares, passa a ser cada vez mais almejada pelo próprio Estado como principal índice de "melhoria" da educação básica, além de servir ao governo como excelente elemento de plataforma política. É nesse exato sentido de "prestação de contas" que parece haver maior coincidência entre os interesses do Estado educador - cujo governo fora eleito pela sociedade - e da sociedade educada - governada pelos seus representantes -, por assim dizer.
} 
teórica existente entre a hipótese apresentada e defendida neste ensaio e o clássico diagnóstico da modernidade oferecido por Max Weber. Pois, em lugar de uma modernidade progressivamente mais plural e heterogênea, como vislumbrava a escola francesa ante o avanço dos tempos modernos, Max Weber sugere o esvaziamento da diversidade ética nas sociedades modernas, onde cada vez mais se constata a emergência de uma ética social hegemônica que logra êxito histórico ao desbaratar todas as demais no curso do seu desenvolvimento (WEBER, 1981).

\section{CONSIDERAÇõES FINAIS}

A especificidade moral da escola pública, de acordo com a perspectiva formulada e defendida neste trabalho, vê-se atualmente atravessada por um processo de desencantamento, num cenário em que se assiste à progressiva homogeneização moral da educação básica no Brasil. Comparativamente, porém, não parece apresentar um quadro de desencantamento tão avançado quanto aquele atravessado pela escola católica, embora tampouco conserve um estado de "pureza moral", por assim dizer, semelhante ao da escola militar. Isso porque, em cada um dos três casos, como se procurou argumentar, as demandas educacionais do alunado, suas expectativas familiares, e os interesses institucionais da escola têm se arranjado de maneiras diferentes nos últimos anos - pressionando mais ou menos em nome de certo pragmatismo transformador. Todos os casos, entretanto, parecem apresentar invariavelmente alguns traços, ainda que de difícil sondagem, de uma educação moral atravessada por aquele movimento de desencantamento. Levado às suas últimas consequências, esse processo se encarregaria de reduzir drástica e concretamente toda diversidade moral das escolas básicas no Brasil atual, homogeneizando as várias peculiaridades e matizes, submetendo-as ao mesmo padrão, semelhante ao da escola-empresa. E isso não se deve a pressões ou influências alheias, exteriores aos interesses das próprias escolas e de seu alunado. Muito antes, trata-se de uma tendência interna, conduzida pelos próprios membros que compõem e dirigem tais instituições, orientados, todavia, por tendências paralelas de ordem política e econômica, em última análise. Desse movimento geral se segue que a educação moral, no âmbito da escola pública, passa a ser progressivamente instrumentalizada, percebida cada vez mais como uma mercadoria ou como um serviço prestado pelo Estado à sociedade, ou a alguns de seus segmentos específicos, tendo em vista a prosperidade pessoal dos alunos no 
futuro. Assim, a socialização moral nas escolas deixa aos poucos de ser percebida como um meio para mudança social - mediante a formação humanística em núcleos de sociabilidade banhados pela moral cidadã - e passa a ser tida como um meio para o sucesso individual. Os discursos e a ética moral da escola pública tendem, assim, a se esvaziar de conteúdos e motivações sublimes, contraindo irresistivelmente certos aspectos da primazia do indivíduo, de valores burgueses, visando sempre melhores resultados em avaliações e concursos vestibulares, para serem apresentados em apelos de cunho cada vez mais publicitário. Não obstante, embora seja tentador sinalizar para o futuro recrudescimento desse processo de desencantamento moral a partir da atual condição em que se encontra a escola pública processo esse catalisado por aquelas potências de oferta e de demanda, ancorada em razões de fundo político e econômico, cada vez mais expressivas -, convém deixar passar em silêncio a questão acerca do destino histórico reservado a esse movimento, que por ora se vê desfilar quase dissimuladamente sob os nossos olhos.

\section{REFERÊNCIAS}

BRASIL. Ministério da Educação (MEC). Secretaria de Educação Básica. Disponível em: $<$ http://portal.mec.gov.br/index.php?option=com_content\&view=article\&id=293\&Itemid $=358>$. Acesso em: 16 jan. 2014.

DURKHEIM, Émile. Educação e sociologia. São Paulo: Melhoramentos, 1955.

DURKHEIM, Émile. Da divisão do trabalho social. São Paulo: Martins Fontes, 1995.

DURKHEIM, Émile. Lições de sociologia. São Paulo: Martins Fontes, 2002.

GERTH, Hans Heinrich.; MILLS, Charles Wright (Org.). Max Weber: ensaios de sociologia. Rio de Janeiro: Guanabara, 1982.

KOHLBERG, Lawrence. Psicologia del desarrollo moral. Bilbao: Editorial Descleés de Brouwer, 1982.

POCHMANN, Marcio. Estrutura social no Brasil: mudanças recentes. Serviço Social \& Sociedade. São Paulo, n. 104, dez. 2010. Disponível em:< http://www.scielo.br/pdf/ sssoc/n104/04.pdf>. Acesso em: 21 ago. 2014.

REDE PITÁGORAS. Conteúdos disponíveis no site: <http://www.redepitagoras.com.br/ pagina/9/home.aspx>. Acesso em: 11 maio 2014. 
DISTRITO FEDERAL. Secretaria de Estado de Educação. Sobre a Secretaria; Leis e Diretrizes; Regimento Escolar das Instituições Educacionais de Rede Pública de Ensino do Distrito Federal. Disponível em: < http://antigo.se.df.gov.br/sites/400/402/00002676.pdf $>$. Acesso em: 10 maio. 2014.

TAVOLARO, Sérgio Barreira de Faria. Existe uma modernidade brasileira?: reflexões em torno de um dilema brasileiro. Revista Brasileira de Ciências Sociais, São Paulo, v.20, n. 59, p. 5-22, out. 2005.

TOCQUEVILlE, Alexis de. A democracia na América. Belo Horizonte : Itatiaia; Edusp, 1998.

WEBER, Max. A ética protestante e o espirito do capitalismo. Brasilia: Editora UnB, 1981.

WEBER, Max. A ciência como vocação. In: GERTH, Hans Heinrich.; MILLS, Charles Wright (Org.). Max Weber: ensaios de sociologia. Rio de Janeiro: Guanabara, 1982. p. 154183

WEBER, Max. Metodologia das ciências sociais. 4. ed. São Paulo: Cortez; Campinas: Ed. UNICAMP, 2001.

WEBER, Max. Economia e sociedade. 4. ed. Brasília: Ed. UnB, 2009. v.1

Como citar este documento:

FERREIRA, Gabriel Lelis da Fonseca; SOUSA, Carlos Alberto Lopes. O desencantamento moral da escola pública: um ensaio de compreensão crítica. ETD - Educação Temática Digital, Campinas, SP, v. 16, n. 2, p. 233-248, maio/ago. 2014. ISSN 1676-2592. Disponível em:

<http://www.fe.unicamp.br/revistas/ged/etd/article/view/6401>. Acesso em: 29 ago. 2014. 